\title{
Effects of Nerve Growth Factor Infusion on Behavioral Recovery and Graft Survival Following Intraventricular Adrenal Medulla Grafts in the Unilateral 6-Hydroxydopamine Lesioned Rat
}

\author{
Valerie K. Bergdall ${ }^{1}$ and Jill B. Becker ${ }^{2}$ \\ ${ }^{1}$ Unit for Laboratory Animal Medicine and ${ }^{2}$ Neuroscience Program, Department of Psychology, and \\ Reproductive Sciences Program, The University of Michigan, Ann Arbor, MI 48104, USA
}

\section{SUMMARY}

NGF was infused into the lateral ventricle of rats with unilateral 6-OHDA lesions of the substantia nigra along with adrenal medulla or control grafts. Treatment effectiveness, as measured by amphetamine-induced turning behavior, indicated that there were no significant differences between treated and control groups in spite of the survival of tyrosine hydroxylase (TH) immunoreactive grafts. Furthermore, adrenal medulla graft survival was not dependent on NGF infusion. These results indicate that TH-positive graft survival is not correlated with behavioral recovery as assessed by amphetamine-induced turning. These results differ from studies which utilized apomorphineinduced turning as a measure of behavioral recovery. We propose that adrenal medulla graft survival alone is not sufficient to promote behavioral recovery in the 6-OHDA lesioned rat.

\section{KEY WORDS}

NGF, adrenal medulla, Parkinson's disease, tyrosine hydroxylase, transplantation, rat

\section{INTRODUCTION}

Transplantation of adrenal medulla tissue into the lateral ventricle of the hemiparkinsonian rat has been reported to result in decreased rotational

Reprint address:

Dr. J.B. Becker

3074B Neuroscience Bldg.

1103 E. Huron Street

Ann Arbor, MI 48109-1687, USA behavior induced by apomorphine $/ 5,10,14 /$ or amphetamine /1/. The decreased amphetamineinduced rotational behavior (but not apomorphineinduced turning) is correlated with enhanced striatal extracellular dopamine, decreased $\mathrm{D}_{2}$ dopamine receptor binding, and an impaired blood-brain barrier at the site of the graft $/ 4 /$. The precise mechanisms mediating these effects, however, are not well understood, as it is not clear that restoration of extracellular dopamine is either necessary or sufficient to promote behavioral recovery of function. For example, there may be trophic effects of adrenal medulla grafts on the surrounding host tissue that produce behavioral recovery. Conversely, induction of an inflammatory response has been shown to produce a non-specific injury-induced trophic effect on the surrounding striatum $/ 6 t$.

Nerve growth factor (NGF) delivered to the lateral ventricle or striatum has been reported to enhance survival of grafted chromaffin cells /14/ and promote behavioral recovery as assessed by apomorphine-induced rotational behavior $/ 10 /$. The purpose of the study reported here was to determine whether continuous intraventricular infusion of NGF in rats with unilateral 6-hydroxydopamine (OHDA) lesions of the substantia nigra would enhance behavioral recovery in adrenal medulla grafted animals, and to determine whether this is correlated with tyrosine hydroxylase $(\mathrm{TH})$ immunoreactivity in the graft and/or host brain.

\section{METHODS AND MATERIALS}

Animals

Adult female Long-Evans rats (Charles River, Indianapolis, IN) were tested with D-amphetamine 
sulfate $(0.85 \mathrm{mg} / \mathrm{kg}$, i.p.) for direction of rotational bias $/ 12 /$. The substantia nigra and medial forebrain bundle on the side contralateral to the preferred direction of turning was then lesioned using 6$\mathrm{OHDA} \cdot \mathrm{HBr}$ at a concentration of $2 \mu \mathrm{g} / \mu \mathrm{l}$ in saline with $0.01 \%$ ascorbic acid. This was infused at a rate of $0.5 \mu \mathrm{l} / \mathrm{min}$ at the following coordinates (from bregma, skull flat): posterior $5.0 \mathrm{~mm}$, lateral 2.0 $\mathrm{mm}$, ventral $7.4 \mathrm{~mm}(8 \mathrm{~min})$; and posterior $3.1 \mathrm{~mm}$, lateral $1.8 \mathrm{~mm}$, and ventral $8.2 \mathrm{~mm}$ (4 min). Animals were allowed to recover for 2 weeks, then tested with amphetamine $(0.85 \mathrm{mg} / \mathrm{kg}$ i.p., $60 \mathrm{~min})$ and with apomorphine $(0.25 \mathrm{mg} / \mathrm{kg}$, s.c., $45 \mathrm{~min})$. Test drugs were never given more than once every 48 hours. Rats which exhibited more than 50 turns per hour following amphetamine, and more than 100 turns per $45 \mathrm{~min}$ following apomorphine were continued in the study. This criterion results in the selection of animals with $>95 \%$ depletion of dopamine in the lesioned striatum $/ 4 /$. The animals then received daily injections of amphetamine (3 $\mathrm{mg} / \mathrm{kg}$, i.p.) every weekday for 2 weeks to sensitize animals to the psychomotor stimulant effects of amphetamine. The sensitization process helps to alleviate the increased rotation rate observed with repeated exposures to amphetamine /13/. Following the sensitization period, the rats were withdrawn from amphetamine for 2 weeks before undergoing pregraft behavioral testing. The behavioral testing consisted of four tests performed at least 48 hours apart. Each test consisted of a 15 minute habituation period followed by a $2 \mathrm{~h}$ period with amphetamine (3 $\mathrm{mg} / \mathrm{kg}$, i.p.) in an automated rotometer (flat-bottom, cylindrical). The mean number of $360^{\circ}$ turns induced by amphetamine was then used as the baseline rate for each animal.

\section{Graft and cannulae placement}

Following the pregraft behavioral testing, the animals were anesthetized with sodium pentobarbital $(30 \mathrm{mg} / \mathrm{kg}$, i.p.) and received grafts of adrenal medulla or adrenal cortex from 1 month-old rat pups as described previously $/ 3 /$ at coordinates anterior $1.0 \mathrm{~mm}$, lateral $1.2 \mathrm{~mm}$, ventral $-5.0 \mathrm{~mm}$. Once the graft was in place, a brain infusion cannula (Alzet) was lowered at the same coordinates and secured in place with dental acrylic cement. The cannula was attached to a subcutaneous $200 \mu \mathrm{l}$ osmotic minipump (Alzet \#2002) filled with nerve growth factor $(0.5 \mu \mathrm{g} / \mu \mathrm{l}$, Harlan Biologics, Madison, Wisconsin) /8/ or cytochrome $c$ (CytoC) $(0.5 \mu \mathrm{g} / \mu \mathrm{l}$, Sigma) with an infusion rate of $0.5 \mu \mathrm{l} / \mathrm{h}$. Animals were assigned to the following groups: adrenal medulla and NGF $(n=10)(\mathrm{AM} / \mathrm{NGF})$, adrenal medulla and CytoC $(n=7)(\mathrm{AM} / \mathrm{CytoC})$, adrenal cortex and NGF ( $\mathrm{n}=9)$ (AC/NGF), and NGF only $(n=7)$. The minipumps were changed every two weeks under metofane anesthesia for a total delivery time of 6 weeks.

\section{Behavioral testing}

Animals were tested in the automated rotometer at 4-5 and 8-9 weeks post graft as described for the pregraft period. The mean of each session was then used to calculate the percent change in rotational behavior [(postgraft-pregraft/pregraft) $\mathrm{X} \mathrm{100 \% ]} \mathrm{at}$ 4 and 8 weeks postgraft.

\section{Histologic analysis}

Half the animals were euthanized with an overdose of sodium pentobarbital and perfused with $4 \%$ paraformaldehyde at 6 weeks postgraft. The remaining animals were similarly euthanized at 10 weeks postgraft. Brains were immediately removed and placed in $4 \%$ paraformaldehyde overnight, then transferred into a $20 \%$ sucrose phosphate buffer for no more than 5 days. Thirty micron sagittal sections were cut on a freezing microtome and stored in $0.2 \%$ sodium azide buffer until stained. Every fourth section was mounted on chrom-alum-subbed slides and stained with Meyer's hematoxylin and eosin. Immunohistochemical staining was done on the remaining sections for tyrosine hydroxylase (TH) using a polyclonal donkey anti-TH antibody (PelFreeze, Rogers, Arkansas).

\section{Polyclonal anti-TH}

The polyclonal anti-TH protocol was modified from procedures described previously /7,11/. Briefly, free floating sections were rinsed in $0.1 \mathrm{M}$ Tris buffered saline (TBS), then transferred to blocking serum containing $5 \%$ normal purified donkey serum (NDS), and $0.3 \%$ Triton-X for one hour. Sections were then incubated with the primary polyclonal anti-TH (PelFreeze) diluted 1:100 with 
TBS containing $2 \%$ NDS and $0.3 \%$ Triton-X for 48 hours, rinsed with TBS and $0.3 \%$ Triton- $X$, then incubated with biotinylated donkey anti-sheep IgG (Jackson Laboratories) diluted 1:200 with TBS containing $2 \%$ NDS and $0.3 \%$ Triton-X for 1 hour. They were then rinsed with TBS, $0.1 \% \mathrm{BSA}$ and incubated for 1 hour in the Vectastain Elite avidinbiotin reagent. Sections were rinsed with $0.1 \mathrm{M}$ Tris buffer and developed with diaminobenzimidine (DAB) reagent $(50 \mathrm{mg} \mathrm{DAB}$ in $100 \mathrm{ml} 0.1 \mathrm{M}$ Tris buffer with $50 \mu \mathrm{l}$ of $8 \% \mathrm{NiCl}$ and $80 \mu \mathrm{l}$ of $30 \%$ $\mathrm{H}_{2} \mathrm{O}_{2}$ ) for 5 minutes. Sections were mounted on chrom-alum subbed slides and coverslipped.

\section{RESULTS}

\section{Rotational behavior}

Behavioral recovery to amphetamine defined as a $20 \%$ reduction in rotational behavior as compared to baseline, was not present at 4 weeks post-surgery in any of the four treatment groups tested. The AM/NGF group tended to have a stable to slight reduction from baseline as compared to the other groups which increased in rotations over time (Figure 1). This was primarily due to one animal in the group which had a $71 \%$ reduction in AMPHinduced turning at 8-9 weeks.

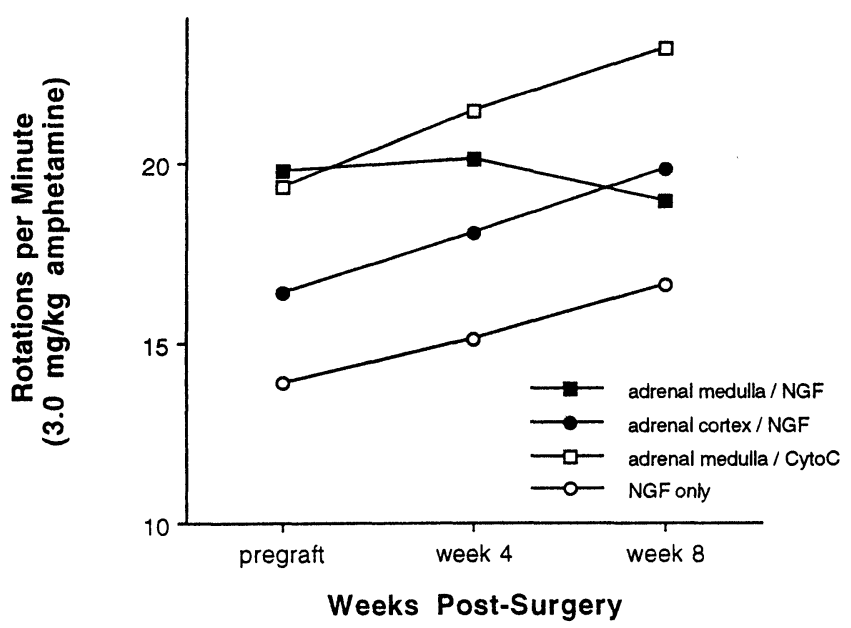

Fig. 1: Amphetamine stimulated rotations in rats prior to surgery and at 4 and 8 weeks post surgery. No significant difference was found between any of the treatment groups.

\section{Histologic analysis}

Sagittal sections were evaluated for the presence of TH-positive cells and fibers, placement of the graft/infusion cannulae, and trauma or inflammation. Anti-TH (PelFreeze) positive grafts were observed in $90 \%(9 / 10)$ of the AM/NGF and $83 \%(8 / 9)$ of the $\mathrm{AM} / \mathrm{CytoC}$ groups (Figure 2). No TH-staining was observed in either the AC/NGF or NGF only groups. Grafts appeared to be adjacent to the striatum in the majority of cases (15/17 rats). The rat which had behavioral recovery to AMPH at 8-9 weeks postgraft, however, had a graft in the 4th ventricle adjacent to the stria terminalis bed.

Hematoxylin and eosin staining indicated the graft appeared to have viable cells with minimal to no inflammatory reaction observed at the graft sites (Figure 2) in all cases. The infusion cannula tract frequently had a small amount of hemorrhage, presumably from the initial placement. An area of ependymal hyperplasia was infrequently noted at the cannula tip. None of these animals was considered to have significant damage $(>30 \%)$ to the striatum. Placement of the cannula was in the lateral ventricle or adjacent striatum in all animals.

\section{DISCUSSION}

Animals receiving AM graft along with NGF infusion had a tendency to show improvement as compared to the other groups. This however was mainly due to one animal which showed a $71 \%$ improvement at 8-9 weeks postgrafting as assessed with AMPH-induced turning. This improvement continued even after NGF infusion ceased. The percent change from baseline for the various groups, however, was not statistically different between the types of treatment used.

Our results differed from a similar study utilizing NGF infusion /10/ in that the rate of grafted chromaffin cell survival was high, even without the addition of NGF. The robust graft survival in our animals may have been due to the lack of inflammatory reaction at the graft site either as a result of surgical technique or specific host differences in the Long-Evans rat. All grafts that were observed stained positive for tyrosine hydroxylase, indirectly indicating dopamine 

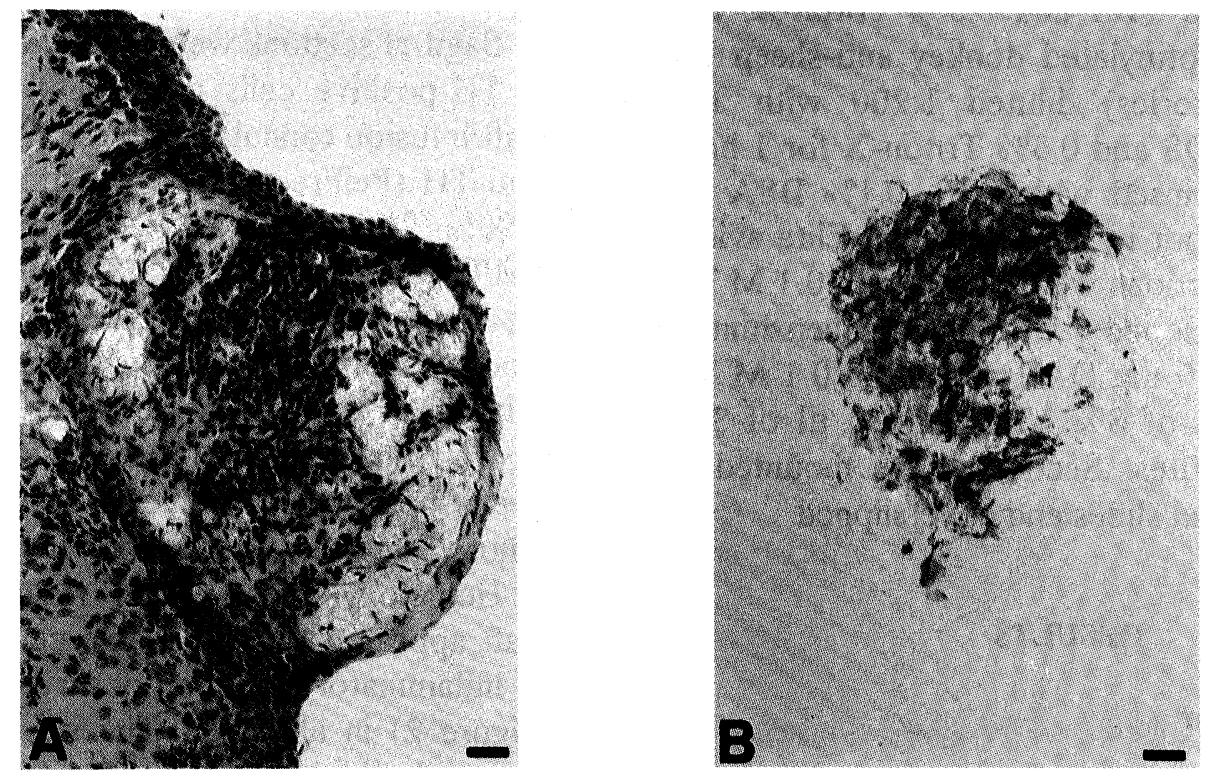

Fig. 2: Photomicrograph of an intraventricular AM graft adjacent to the striatum (A-B). A: Hematoxylin and eosin stained section illustrating viable chromaffin cells with minimal to no inflammatory reaction. B: tyrosine hydroxylase immunohistochemical staining (Pelfreeze anti-TH). Grafted chromaffin cells contain tyrosine hydroxylase indicating their potential ability to produce dopamine. Note that the graft does not have projections into the host tissue. (Scale bar = 110 microns.)

production; however, this was not correlated with behavioral recovery to amphetamine. The results of our study are similar to those of Brown and Dunnett $/ 2 /$ in which adrenal medulla grafting did not decrease amphetamine-induced turning in the hemiparkinsonian rat. Previous work in our laboratory has demonstrated behavioral recovery to amphetamine after adrenal medulla grafts $/ 3,4 /$. This study differed from the previous work in our laboratory, however, in that apomorphine was not administered as part of the post-graft behavioral analysis. Furthermore, the presence of the infusion cannula in the striatum on the lesioned side may have resulted in a sufficient amount of damage which overshadowed any benefit the graft may have had.

Previous studies in which NGF was found to be beneficial for behavioral recovery after adrenal medulla grafts have used apomorphine-induced turning as the behavioral assessment technique. It is likely, however, that amphetamine-induced turning may involve a different mechanism of recovery than for apomorphine, as suggested previously by Curran et al. /4/. Amphetamine works presynaptically as a dopamine agonist to enhance dopamine release, whereas apomorphine is a postsynaptic receptor agonist acting on the supersensitive dopamine receptors on the lesioned side. Recovery to apomorphine, therefore, suggest that the dopamine receptors are becoming less sensitive. The results of previous studies in which NGF treatment in animals with adrenal medulla grafts resulted in decreased apomorphine-induced turning suggest that NGF may induce decreased DA receptor sensitivity, but this may not be associated with a generalized behavioral recovery. If amphetamine-induced turning behavior is a better assessment of clinical efficacy of transplantation, as we have suggested previously $/ 4 /$, the utilization of NGF-enhanced adrenal medulla grafts as a treatment for Parkinson's disease does not appear to be efficacious. 


\section{ACKNOWLEDGEMENTS}

The authors would like to thank Dr. Denise Jackson for suggestions on the immunocytochemistry protocols and Mr. T.D. Butzbaugh for his technical assistance on this project. This research was supported by a grant from the USPHS, NS 22157 to JBB and by a grant from NIH 5T32RR07008.

\section{REFERENCES}

1. Becker JB, Freed WJ. Adrenal medulla grafts enhance functional activity of the striatal dopamine system following substantia nigra lesion. Brain Res 1988; 462: 401-406.

2. Brown VJ, Dunnett SB. Comparison of adrenal and foetal nigral grafts on drug-induced rotation in rats with 6-OHDA lesions. Exp Brain Res 1989; 78: $214-$ 218.

3. Curran EJ, Becker JB. Changes in blood-brain barrier permeability are associated with behavioral and neurochemical indices of recovery following intraventricular adrenal medulla grafts in an animal model of Parkinson's disease. Exp Neurol 1991; 114: 184192.

4. Curran EJ, Albiri RL, Becker JB. Adrenal medulla grafts in the hemiparkinsonian rat: Profile of behavioral recovery predicts restoration of the symmetry between the two striata in measures of preand postsynaptic dopamine function. J Neurosci 1993; 13: 3864-3877.

5. Freed WJ, Morihisa JM, Spoor E, Hoffer BJ, Olson L. Seiger A, Wyatt RJ. Transplanted adrenal chromaffin cells in rat brain reduce lesion-induced rotational behaviour. Nature 1981; 292: 351-352.
6. Freed WJ, Poltorak M, Becker JB. Intracerebral adrenal medulla grafts: A review. Exp Neurol 1990; 110: 139-166.

7. Haycock JW, Waymire JC. Activating antibodies to tyrosine hydroxylase. J Biol Chem 1982; 257: 94169423.

8. Hefti F. IVth International Symposium on Neural Transplantation Meeting. Washington, D.C., July 1992.

9. Hefti F, Melamed E, Sahakian BJ, Wurtman RJ. Circling behavior in rats with partial, unilateral nigrostriatal lesions: Effect of amphetamine, apomorphine, and DOPA. Pharmacol Biochem Behav 1980; 12: 185188.

10. Pezzoli G, Fahn S, Dwork A, Truong DD, de Yebenes JG, Jackson-Lewis V, Herbert J, Cadet JL. Nonchromaffin tissue plus nerve growth factor reduces experimental parkinsonism in aged rats. Brain Res 1988; 459: 398-403.

11. Renfroe J, Chronister R, Haycock J, Waymire J. The localization of tyrosine hydroxylase-like immunoreactivity in the central nervous system: methodological considerations. Brain Res Bull 1984; 13: 109-126.

12. Robinson TE, Becker JB. The rotational behavior model: asymmetry in the effects of unilateral 6-OHDA lesions of the substantia nigra in rats. Brain Res 1983; 264: 127-131

13. Robinson TE, Becker JB, Presty SK. Long-term facilitation of amphetamine-induced rotational behavior and striatal dopamine release produced by a single exposure to amphetamine: sex differences. Brain Res 1982; 253: 231-241.

14. Stromberg I, Herrera-Marschitz M, Ungerstedt U, Ebendal T, Olson L. Chronic implants of chromaffin tissue into the dopamine-denervated striatum. Effects of NGF on graft survival, fiber growth and rotational behavior. Exp Brain Res 1985; 60: 335-349. 

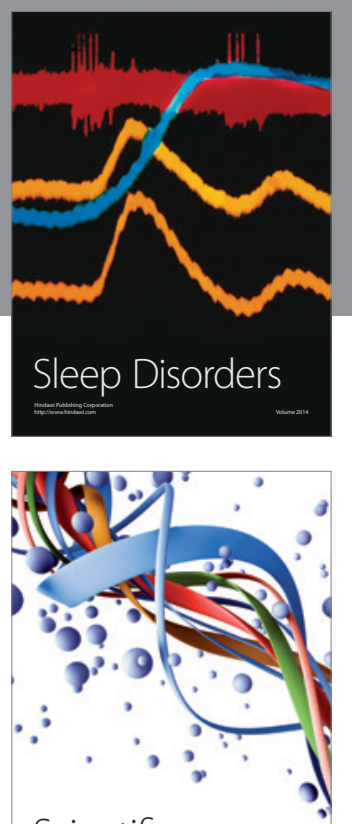

Scientifica
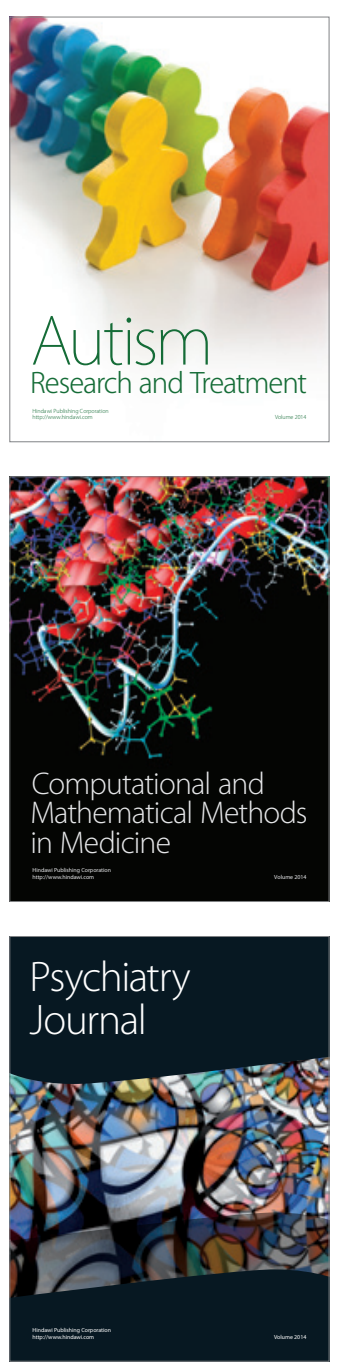
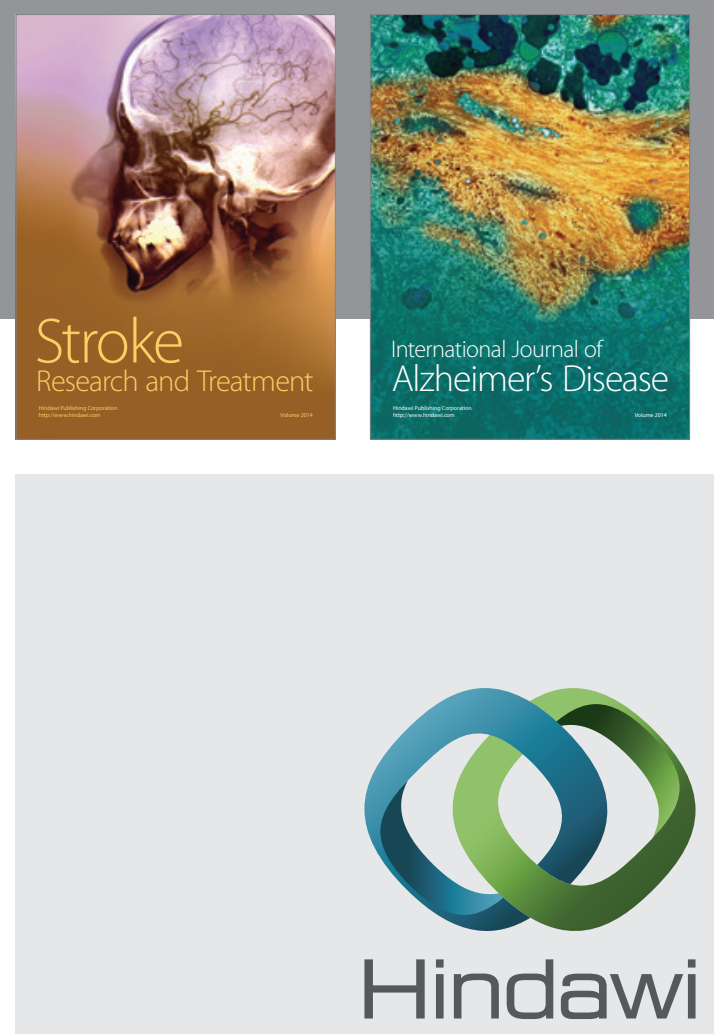

Submit your manuscripts at

http://www.hindawi.com
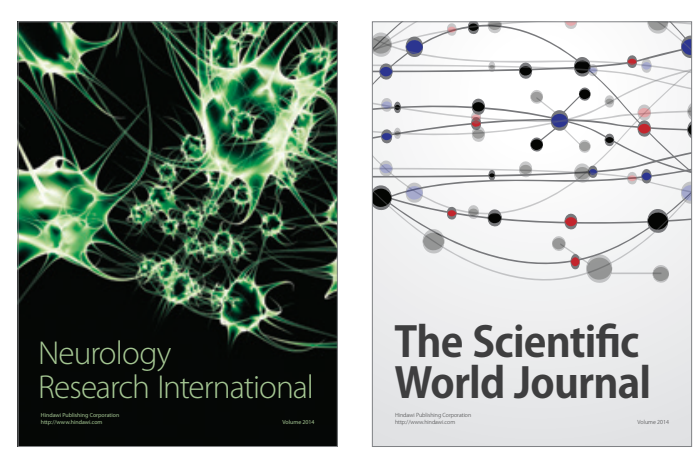

The Scientific World Journal

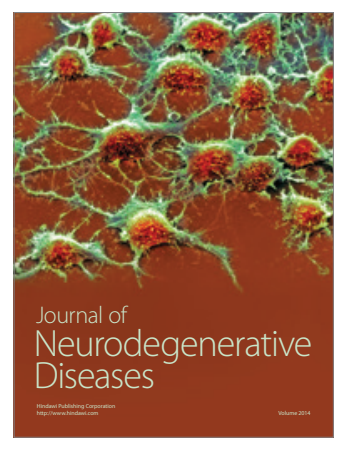

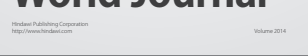

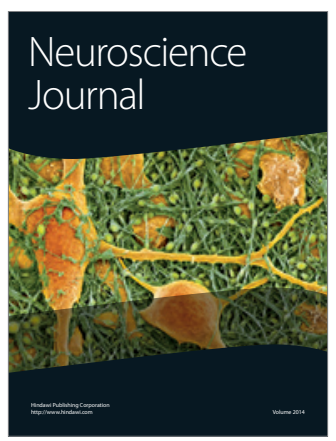

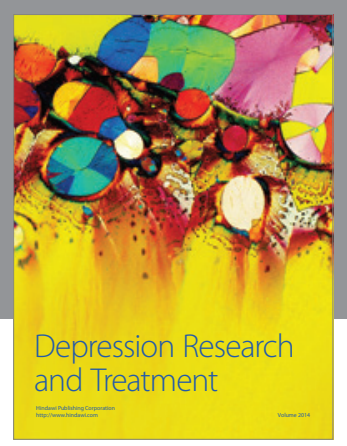
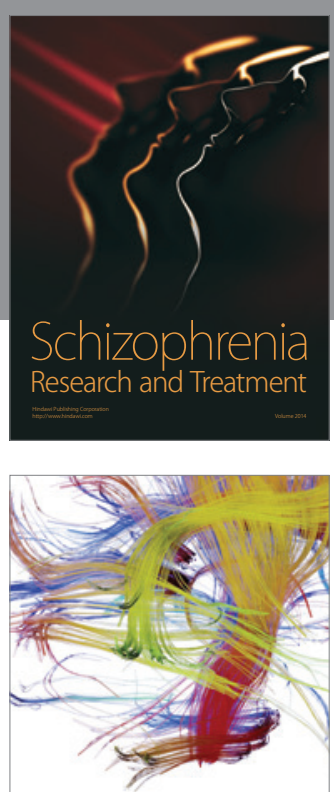

Brain Science

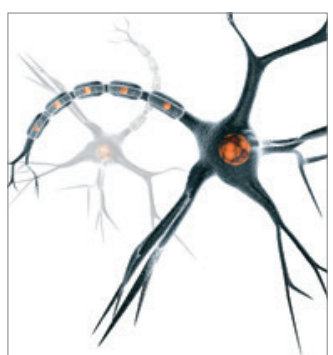

Neural Plasticity
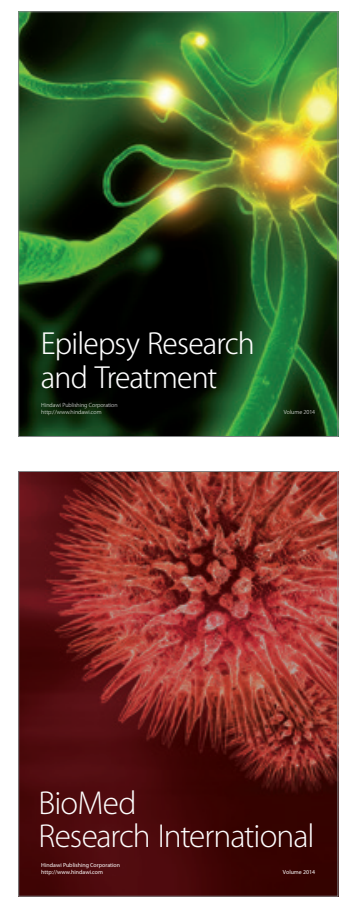

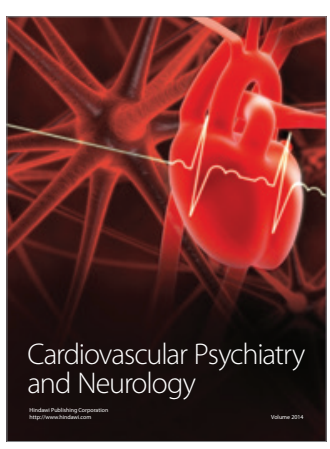

Parkinson's

Disease
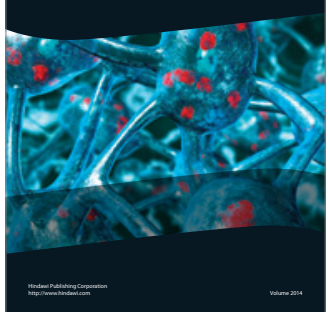